\title{
Outstanding Impact Resistance of Post-Consumer HDPE/Multilayer Packaging Composites
}

\author{
Silvia Luciana Favaro1, Antonio Guilherme Basso Pereira², Janaina Rodrigues Fernandes ${ }^{3}$, \\ Orlando Baron ${ }^{3}$, Cleiser Thiago Pereira da Silva ${ }^{3}$, Murilo Pereira Moisés ${ }^{4}$, \\ Eduardo Radovanovic ${ }^{3 *}$
}

\author{
${ }^{1}$ Departamento de Engenharia Mecânica, Universidade Estadual de Maringá, Maringá, PR, Brazil \\ ${ }^{2}$ Universidade Tecnológica Federal do Paraná (UTFPR), Dois Vizinhos, PR, Brazil \\ ${ }^{3}$ Departamento de Química, Universidade Estadual de Maringá, Maringá, PR, Brazil \\ ${ }^{4}$ Universidade Tecnológica Federal do Paraná (UTFPR), Apucarana, PR, Brazil \\ Email: *eradovanovic@uem.br
}

How to cite this paper: Favaro, S.L., Pereira, A.G.B., Fernandes, J.R., Baron, O., da Silva, C.T.P., Moisés, M.P. and Radovanovic, E. (2017) Outstanding Impact Resistance of Post-Consumer HDPE/Multilayer Packaging Composites. Materials Sciences and Applications, 8, 15-25.

http://dx.doi.org/10.4236/msa.2017.81002

Received: July 25, 2016

Accepted: January 2, 2017

Published: January 5, 2017

Copyright $\odot 2017$ by authors and Scientific Research Publishing Inc. This work is licensed under the Creative Commons Attribution International License (CC BY 4.0).

http://creativecommons.org/licenses/by/4.0/

(c) (i) Open Access

\begin{abstract}
New recycling alternative for multilayer films was successfully presented. Food packaging formed from different materials is difficult to recycle. The use of aluminum, glass, paper, paints, varnishes, and other materials in the rolling processes from plastic packaging is intended to optimize the efficiency of packaging. Nevertheless, these materials prevent the recycling of packaging because they become contaminants to the recycling process. Food multilayered packaging containing poly (ethylene terephthalate) PET, poly (ethylene) $\mathrm{PE}$ and aluminum was used as filler in the preparation of composites with post-consumer high density polyethylene matrix. Composites containing up to $50 \mathrm{wt} \%$ of filler were feasible to prepare, allowing the obtention of a material with varied mechanical and thermal properties. This feature allows the preparation of composites suitable for specific application. The addition of multilayer matter in the polyethylene matrix provided a material with excellent mechanical properties such as higher tensile impact strength $(148 \mathrm{~J} / \mathrm{m})$ and elasticity (350 MPa) as compared to pure polyethylene $(40 \mathrm{~J} / \mathrm{m}$ and 450 $\mathrm{MPa})$.
\end{abstract}

\section{Keywords}

Multilayer Packaging, Polymer-Matrix Composites, Recycling, Mechanical Properties

\section{Introduction}

The plastic manufacturing industry significantly contributed to developing the 
human society in the past decades. The low production cost of polymers, the low density, the mechanical features, among other properties, are the main appealing characteristics to render plastics as engineering materials for uses in many sectors of production e.g. automobile, aviation, electronics, transportation, storage containers, etc. Undoubtedly, the plastic packaging films division is one of the most important branches of polymer industry with product shipment value in 2013 of ca. 12 billion dollars only in USA [1] with continuous growth estimated to reach 20 billion pounds in 2020 [2].

Flexible multilayer films have revolutionized the food industry by expanding products shelf life, maintaining texture, flavor, and humidity, among other aspects. For this, different properties are required, including barrier to water vapor, gas, flavor, light, as well as flexibility or stiffness. These properties are hardly ever obtained using only one polymer. While one polymer can be advantageous for having mechanical resistance, it can be extremely inconvenient in relation to other properties, such as transparency and permeability [3] [4]. Thus, the food packaging industry needs to develop multilayer films, with specific chemical, physical and mechanical properties, containing different polymers either by lamination or co-extrusion [5].

In spite of the advantages achieved with the use of multilayer films, the recycling of such a kind of material is very difficult. The separation and classification processes of these films are arduous due to the polymers similarity: e.g. density and visual aspects. Multilayer films are composed of polymers incompatible for extrusion recycling [6] [7] [8] [9]. Film containing poly (ethylene terephthalate) (PET) is an interesting example. The extrusion of PET requires higher temperatures than that used for the extrusion of other polymers, such as polyethylene (PE) and polypropylene (PP). As a result, these films are gathered in the factory or turned into waste. Although, the energy recovery through incineration of post-consumer wrapping is not recognized as the most interesting process due to the release of green house gases and other pollutants, it is the only available alternative for dealing with multilayer packing wastes nowadays.

The continuous world population growth increases the demands of multilayer packaging, and with the estimated 9 billion people in 2050, packaging wastes have become a great environmental concern [1]. Therefore, there is an urge to develop alternative methods for recycling such kind of material. The preparation of composite materials has become very attractive in the mechanical recycling of plastic wastes [10] [11]. This approach may generate materials with specific mechanical properties and also allow the preparation of highly value-added products from plastic wastes [12] [13] [14] [15] [16].

This work presents an excellent alternative for recycling post-consumer multilayer wastes containing PET, PE and aluminum. Composite materials were prepared by using ground multilayer films as reinforcement phase in recycled high density polyethylene (PE) matrix. PET and aluminum worked as reinforcing fillers providing better mechanical properties, while PE improved the adhesion between matrix and fillers. The composites were characterized by scanning 
electron microscopy (SEM), thermal analysis, water uptake, tensile, flexural and IZOD impact tests. The approach presented here offers new possibilities for process and product development from flexible multilayer wastes contributing for mitigating future environmental issues.

\section{Experimental}

\subsection{Composites Preparation}

\subsubsection{Extrusion}

Previously, metalized multilayer packaging and post-consumer high-density polyethylene (PE) were washed and dried at $80^{\circ} \mathrm{C}$ for $12 \mathrm{~h}$. Then, both materials were ground $(4 \mathrm{~mm} \times 4 \mathrm{~mm}$ ) using a knife mill (Brand RONI, Model NFA 1533, Brazil).

The components were mixed in a monoscrew extruder (Wortex WE X30, Brazil) using screw $\mathrm{L} / \mathrm{D}=32$. The cylinder temperature was adjusted to $120^{\circ} \mathrm{C}$ (feeding zone), $130^{\circ} \mathrm{C}, 150^{\circ} \mathrm{C}, 180^{\circ} \mathrm{C}$ and $185^{\circ} \mathrm{C}$ (outing zone) for the five heating zones and an average rotation of $102 \mathrm{rpm}$ was used for all formulations.

The extruded material was water-cooled down to room temperature and then, ground into pellets in a mill (Primotécnica Model PGS 50, Series PGS 1/1, Brazil).

\subsubsection{Injection}

The samples for mechanical tests were obtained by injection molding (ARBURG, $221 \mathrm{~K} 250-75$, Germany) at $180^{\circ} \mathrm{C}$ and injection pressure of 1500 bar. The prepared composites were labeled as in the example: PE/Multi10, where PE represents the recycled high density polyethylene matrix with $10 \mathrm{wt} \%$ of multilayer packaging as reinforcement. Five different composites formulations (10, 20, 30, 40 and $50 \mathrm{wt} \%$ of multilayer packaging in PE matrix) were prepared.

\subsection{Characterization Techniques}

\subsubsection{Izod Impact Testing}

The notched Izod impact strength tests were performed according to ASTM D 256-00 A at room temperature in an EMIC-Al testing machine using a $2.7 \mathrm{~J}$ hammer. The values obtained are averaged measurements of five samples.

\subsubsection{Water Uptake}

Water uptake measurements were based on ASTM D570-98, with immersion time of 3 weeks at $25^{\circ} \mathrm{C}\left( \pm 2^{\circ} \mathrm{C}\right)$.

\subsubsection{Thermogravimetric Analysis (TG)}

TG was performed on $6 \mathrm{mg}$ sample pieces placed into platinum pans (Shimadzu TGA-50), heated at $10^{\circ} \mathrm{C} / \mathrm{min}$ under flowing nitrogen $(20 \mathrm{~mL} / \mathrm{min})$.

\subsubsection{Tensile Testing}

Tensile strength and modulus assays were performed according to the ASTM D-638. The samples were submitted to tensile tests in an EMIC DL $2000 \mathrm{ma}-$ chine at a constant cross-speed of $50 \mathrm{~mm} / \mathrm{min}$. Tensile properties were deter- 
mined for eight samples of each composition.

\subsubsection{Flexural Testing}

Flexural strength and modulus were determined using the three-point bending test method following the ASTMD-790-00, using $63 \mathrm{~mm}$ span in a $5 \mathrm{kN}$ load.

\subsubsection{Scanning Electron Microscopy (SEM)}

Composite images from fractured surface (samples used in the Izod impact testing) were taken using a scanning electron microscope (Shimadzu SS $550 \mathrm{Su}$ perscan). The samples were gold-sputtered and observed under different magnifications.

\subsection{Determination of Multilayer Packaging Composition}

$1 \mathrm{~g}$ of milled multilayer packaging was added in a Becker containing $10 \mathrm{~mL}$ of a $2.5 \mathrm{wt} \% \mathrm{NaOH} /$ acetone solution. The mixture was stirred for $2 \mathrm{~h}$ at $200 \mathrm{rpm}$ to complete the film delamination and dissolution of aluminum. The mixture was added to $20 \mathrm{~mL}$ of water, and PE (floating) and PET (precipitated) were separated, dried and weighed. Aluminum mass was obtained by mass difference, after obtaining PE and PET composition in the sample, and by gravimetric analysis of $10 \mathrm{~g}$ of the multilayer film heated at $600^{\circ} \mathrm{C}$ in muffle furnace.

\section{Results and Discussion}

The multilayer packaging is composed of a layer of aluminum $(8 \mu \mathrm{m})$ between a PET printed layer $(12 \mu \mathrm{m})$ and a layer $(41 \mu \mathrm{m})$ of a blend $(70 / 30)$ of linear low-density polyethylene (LLDPE) and low-density polyethylene (LDPE). The packaging was obtained by lamination using an adhesive with two-component solvent-based polyurethane adhesive. The packaging composition was determined after delamination: $19 \pm 1 \mathrm{wt} \%$ of PET, $47 \pm 1 \mathrm{wt} \%$ of PE and $34 \pm 1 \mathrm{wt} \%$ of $\mathrm{Al}$ were found.

\subsection{Scanning Electron Microscopy Characterization}

The prepared composites were visually similar to post-consumer high-density polyethylene (PE) presenting high level of homogeneity, smooth surface and greenish color, at naked eyes. However, the color depended on the original multilayer packaging used. At the micro dimension, the composite morphology, the fillers distribution inside the matrix, as well as the adhesion between matrix and filler were evaluated by analyzing the fracture of the test specimen after the tensile test. The SEM images (Figure 1(a)) show the presence of PET films and aluminum layers in the composite material. During the grinding, extrusion and injection steps, the multilayer film was decomposed into its primary components: PET, PE and aluminum. The melting of PE separated it from the Al. Therefore, for all composites formulation the "multilayer films" were not found in its original state, but rather as PET and aluminum phases. In other words the films were delaminated. However, the adhesion between PET and PE was efficient as observed in Figure 1(b). 


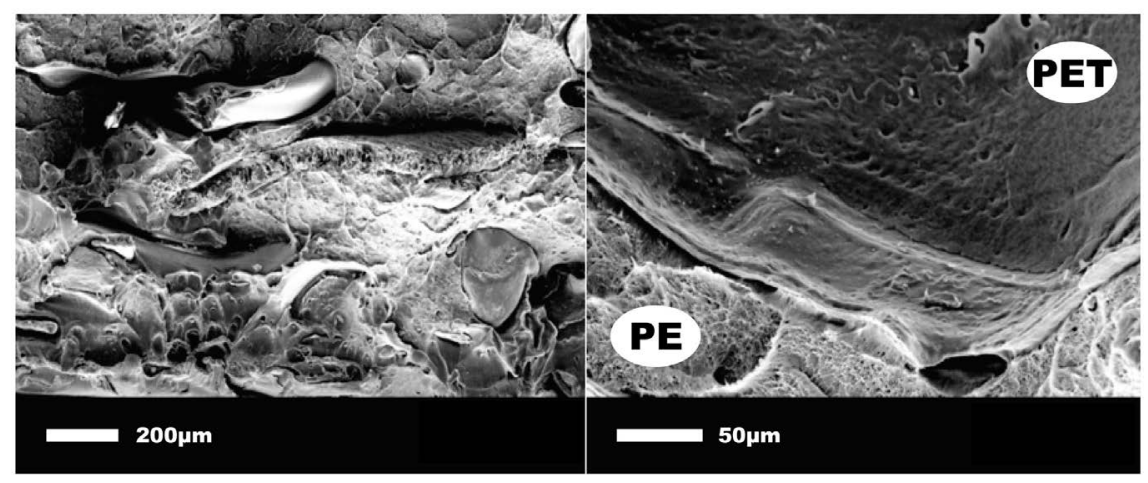

(a)

(b)

Figure 1. SEM micrographs of composite PE/Multi10 with magnification $60 \times$ (a) and $300 \times(b)$.

\subsection{Water Uptake Characterization}

Table 1 shows the results for the water uptake assays of PE and composites. Although composites presented small values for water uptake, those values are considerably superior to that for PE $(0.032 \%)$. This fact is explained by the presence of aluminum oxide that has great affinity with water and polar substances, and in general has a layer of adsorbed water in its surface. The higher water uptake may also be a result of increased porosity of composites generated by the presence of aluminum, and the higher the amount of filler (multilayer packaging), the higher water uptake and the time to reach equilibrium.

\subsection{Thermal Characterization}

Figure 2 shows TGA curves obtained for PE and for composites containing 10, 30 and $50 \mathrm{wt} \%$ of filler. At the level of $10 \%$ weight loss (T10), a small decrease in the thermal stability of composites in relation to PE was observed. The T10 for PE was $452^{\circ} \mathrm{C}$, while for the composites T10 was ca. $440^{\circ} \mathrm{C}$. Another interesting feature obtained from TGA curves is the residual mass after burning. As the amount of multilayer was increased, there was an increase in the amount of inorganic matter (aluminum and aluminum oxide) and therefore the residual mass (ashes) increased gradually, 1\%, 6\%, 11\% and 18\%, corresponding to PE, PEmult10, PE-mult30 and PE-mult50, respectively. Considering each TGA run requires ca. $6 \mathrm{mg}$ (only part of the all composite sample) and the ashes obtained at the end of the process increased consistently with increasing the amount of filler, that data suggest homogeneous distribution of the filler inside de matrix.

\subsection{Tensile, Flexural and Impact Strength Characterization}

The mechanical properties were assessed through tensile, flexural and impact strength tests. Figure 3 presents the results of tensile strength test. The maximum stress at breaking decreased with the increase of the amount of multilayer material in the composite. This effect is very clear at $50 \%$ of filler, composition in which the tensile strength decreased to the half of that observed for the PE (20 $\mathrm{MPa})$. The elongation at break results showed that an addition of $10 \%$ of filler 
Table 1. Water uptake until saturation point for different composites at room temperature.

\begin{tabular}{ccccc}
\hline \multirow{2}{*}{ Samples } & \multicolumn{4}{c}{ Water absorption at different times (wt\%) } \\
\cline { 2 - 5 } & 24 hours & 1 week & 2 weeks & 3 weeks \\
\hline PE/10mult & 0.09 & 0.09 & 0.20 & 0.20 \\
PE/20mult & 0.11 & 0.23 & 0.23 & 0.23 \\
PE/30mult & 0.29 & 0.44 & 0.56 & 0.56 \\
PE/40mult & 0.79 & 1.21 & 1.59 & 1.62 \\
PE/50mult & 1.23 & 2.16 & 2.79 & 2.98 \\
\hline
\end{tabular}

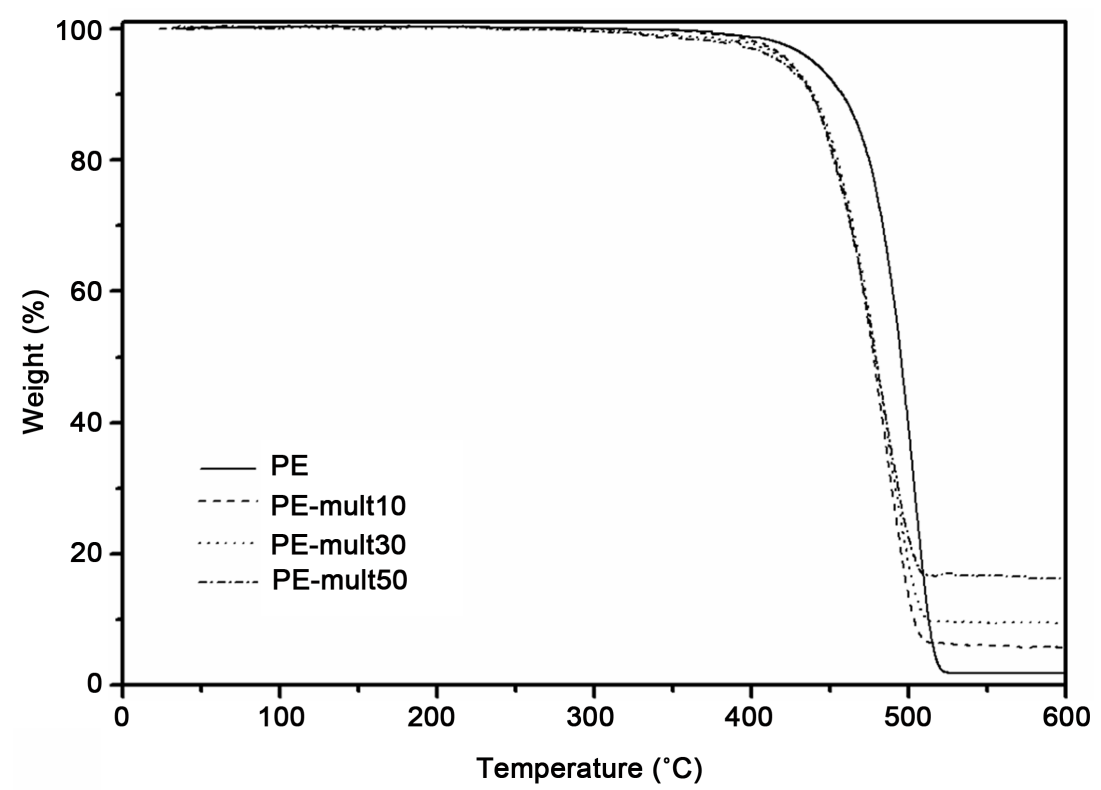

Figure 2. TGA curves of PE and composites: PE/Multi10, PE/Multi30 and PE/Multi50.

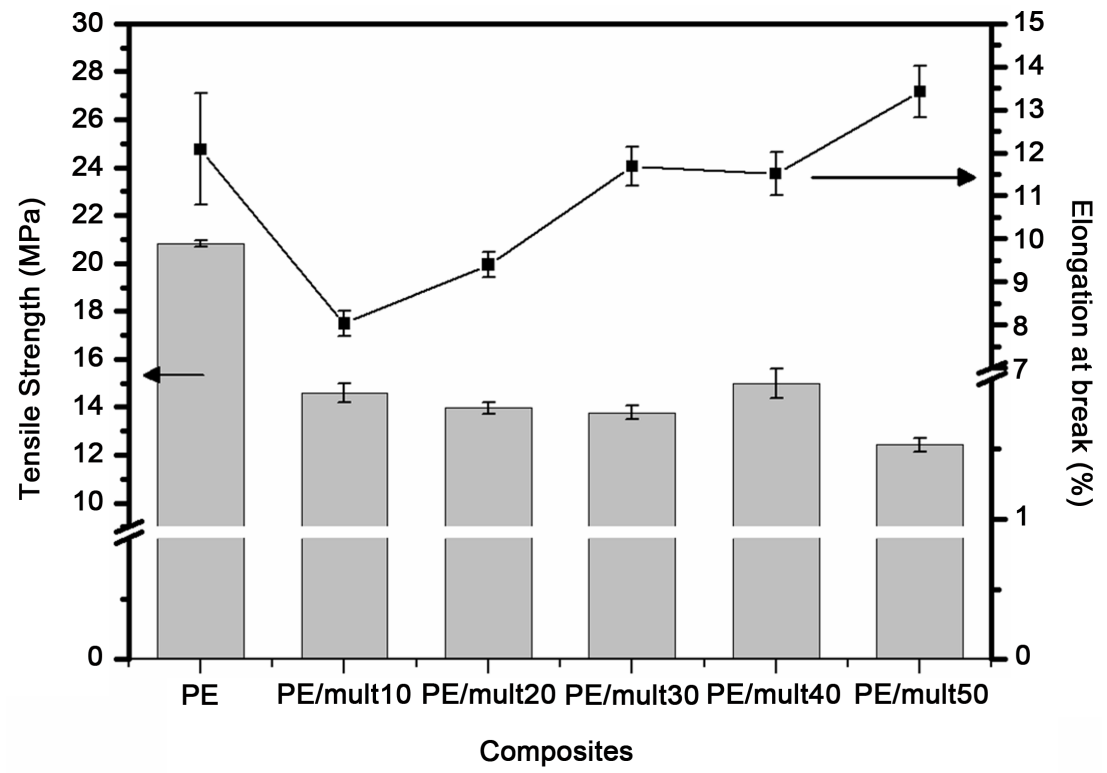

Figure 3. Tensile properties of PE and PE/multilayer packaging composites. 
decreased ca. $6 \%$ the composite elongation at break. However, opposite behavior was observed for further increasing in the filler amount. The elongation at break for the composite at $50 \mathrm{wt} \%$ of filler slightly overcame the value observed for PE (12\%). The addition of filler (aluminum and PET) induced higher stiffness to the composite in relation to PE, so for the composite at $10 \%$ of filler smaller elongation at break was observed, which shows that at such formulation the features of aluminum and PET predominated. However, for the composites with larger amounts of multilayer, the characteristics of LLDPE and LDPE prevailed over aluminum and PET decreasing the stiffness of the composites. As a consequence of such result, the elastic modulus value (Figure 4) presented a small increase for the composite at $10 \%$ of multilayer when compared to the pure matrix, and decreased as the multilayer amount was increased. This fact indicates that it is possible to obtain more elastic material by increasing the amount of multilayer in the PE matrix.

For a better understanding of such results one can observe the data on Table 2 [17] [18], in which different kinds of polyethylene present distinct mechanical

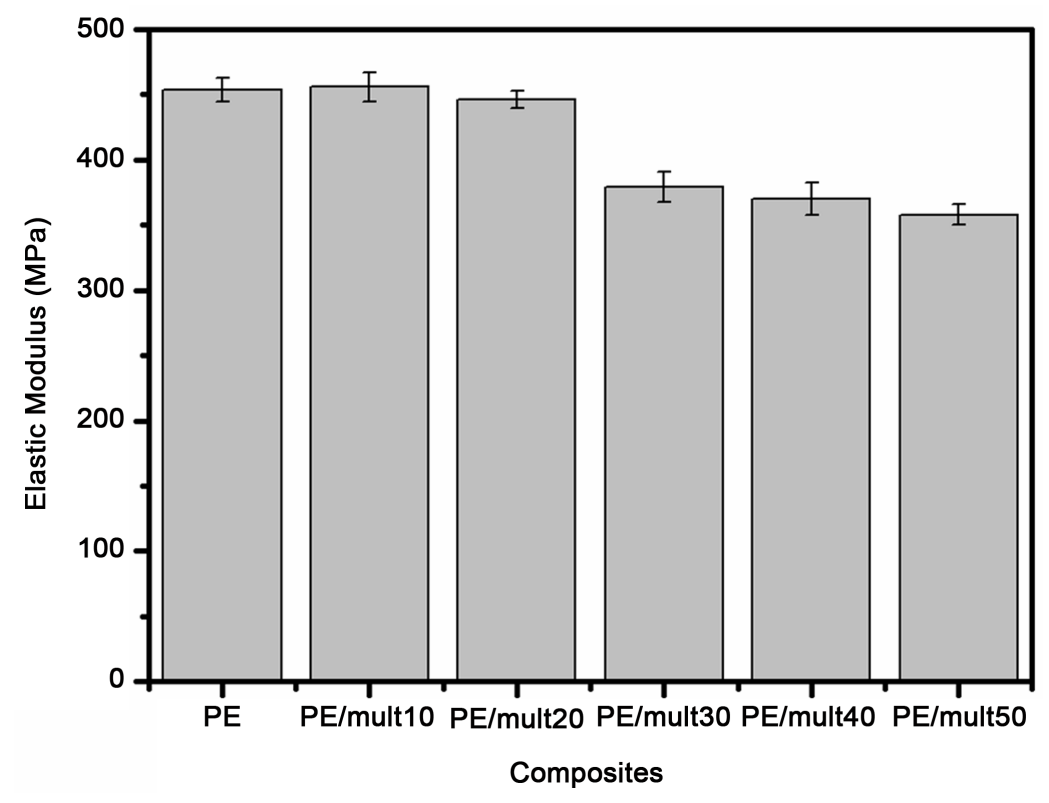

Figure 4. Elastic modulus of PE and PE/multilayer packaging composites.

Table 2. Properties of different types of polyethylene.

\begin{tabular}{ccccc}
\hline Properties & LLDPE $^{*}$ & LDPE $^{*}$ & HDPE $^{*}$ & HDPE-pc \\
\hline Density $\left(\mathrm{g} / \mathrm{cm}^{3}\right)$ & $0.910-0.925$ & $0.915-0.935$ & $0.941-0.967$ & - \\
Melting (0C) & $121-125$ & $106-112$ & $130-133$ & 130 \\
Stress $(\mathrm{MPa})$ & $14-21$ & $7-17$ & 18 & 20 \\
Elongation (\%) & $200-1200$ & $100-700$ & $20-100$ & 12 \\
Impact resistance (J/m) & - & $0.67-21$ & $27-160$ & 42 \\
Elastic modulus (MPa) & $100-200$ & $102-240$ & $960-1000$ & 453 \\
\hline
\end{tabular}

${ }^{\star}$ According to references 17 and 18. 
properties. Thus, the small values of strain and elastic modulus as well as the great values for elongation presented by LDPE and LLDPE induced more flexibility to the composites as the filler amount was increased. The orientation of the polymeric chains has a strong effect on the mechanical properties of a polymer. For instance, materials produced from HDPE highly oriented are ca. 10fold tougher than those materials made from non-oriented polymers, because the orientation increases the chains packing and, as a consequence, improves the stiffness. When compared to HDPE, the LLDPE presents lower tensile strength and stiffness as the degree of branching is increased, but the impact strength and tearing are higher (suitable for film preparation). However, the flexural features were not affect as much as tensile and impact strength. Therefore, only small variations on the mechanical behavior of composites were observed in the flexural tests as compared to the PE and a small increase in the flexural strength (Figure 5) was observed for the composite at $10 \%$ of multilayer, while for other formulations the maximum strain was lower than that for the PE. The flexural modulus (Figure 5) increased for composites at multilayer composition higher than $10 \%$.

The most remarkable finding is related to impact strength observed for the composites, as displayed in Figure 6. Outstanding improvement in the impact strength was observed for all formulation and this fact was directly related to the amount of filler added. Astonishingly, at as low as $10 \mathrm{wt} \%$ of filler the impact strength was ca. twice bigger than that observed for PE $(40 \mathrm{~J} / \mathrm{m})$ reaching ca. 150 $\mathrm{J} / \mathrm{m}$ at $50 \mathrm{wt} \%$ of filler. The presence of aluminum and PET had synergic effect and acted as a barrier to the fault propagation [18]. The presence of LLDPE and LDPE also contributed to the increase of impact strength behavior as an energy absorber material [19]. Comparing the multilayer/PE composites to another PE composite prepared in our laboratory using three different fillers, sisal fibers

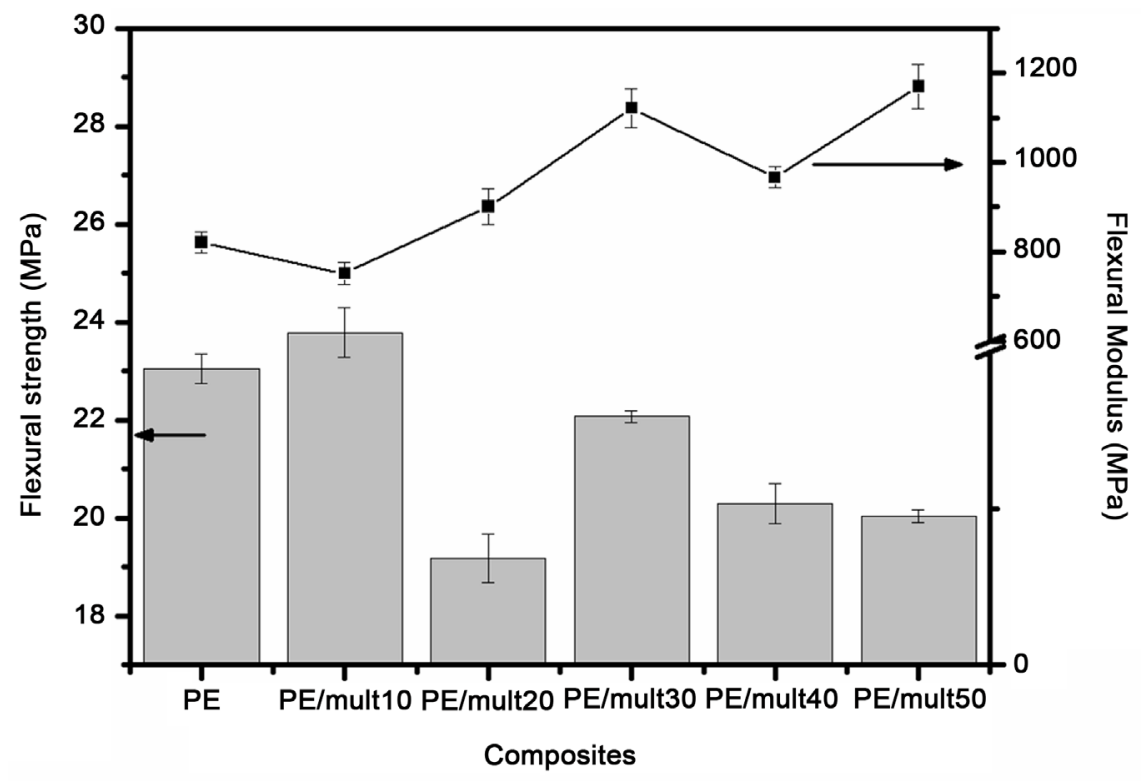

Figure 5. Flexural properties of $\mathrm{PE}$ and $\mathrm{PE} /$ multilayer packaging composites. 


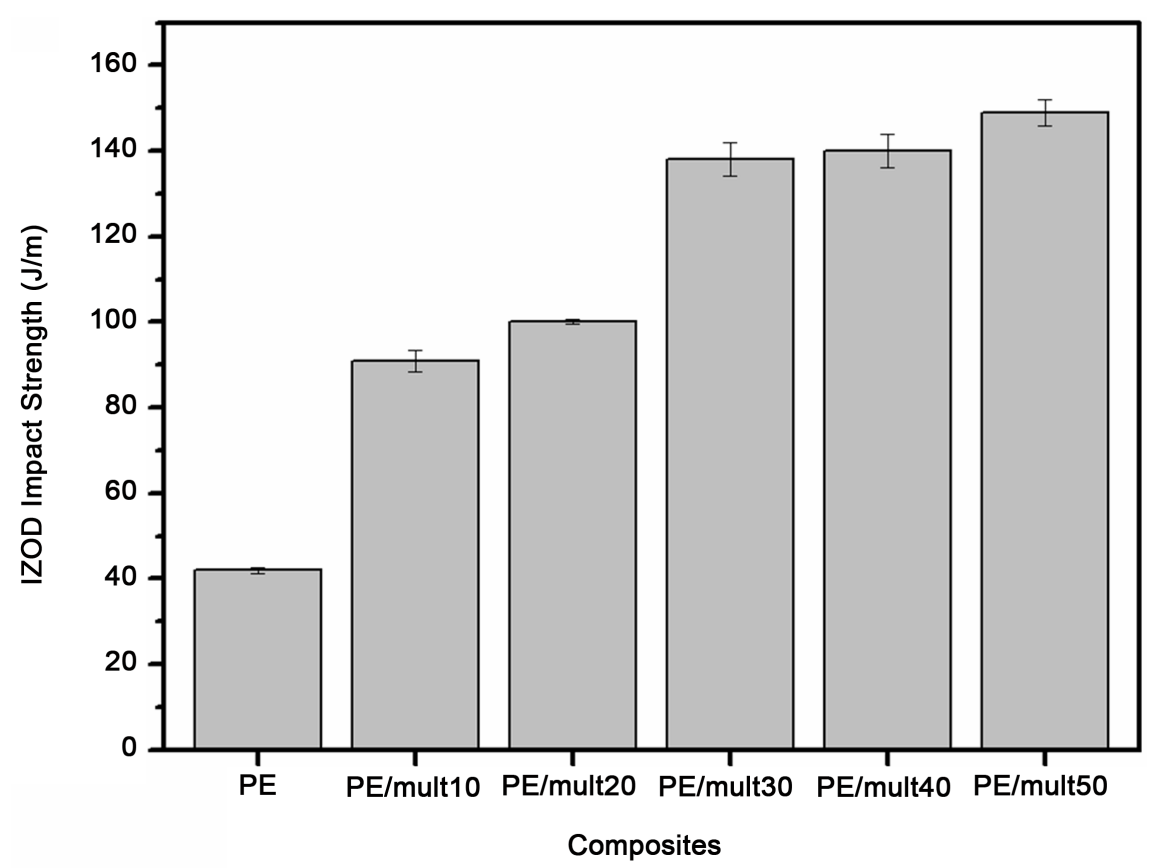

Figure 6. Izod impact properties of PE and PE/multilayer packaging composites.

[14], rice husk [15], and sugarcane bagasse [20], with $10 \mathrm{wt} \%$ of filler, the synergistic effect on impact resistance of multilayer film on PE is evident. The composites prepared with biomass fillers presented around $60 \mathrm{~J} / \mathrm{m}$ of impact strength while PE-mult 10 presented $91 \mathrm{~J} / \mathrm{m}$, reaching $148 \mathrm{~J} / \mathrm{m}$ on PE-mult50.

Therefore, from the methodology developed is possible to achieve a final composite material with completely different and improved properties from the original PE. For instance, the outstanding impact strength showed by the composites allows it to be employed in situations in which that property is required, for instance as a car bumper, among others.

\section{Conclusions}

The addition of multilayer matter in the PE matrix provided a material with excellent mechanical properties such as tensile impact strength and high elasticity. The presence of different components in the multilayer packaging that was the main obstacle preventing its recycling, became the key feature to develop a material with outstanding superior properties than those presented by commercial products. The composites presented low water uptake and high thermal stability. One of the greatest advantages in the preparation of such composites was the possibility to range the formulation PE/filler up to $50 \%$ of filler providing final materials with tailored mechanical properties, according to their composition.

The high toughness presented by the developed composite allows its application in the automobile industry, for instance, for bumper production, piece that requires high impact tensile strength as well as in the production of internal parts of vehicles. Besides, the composites could be applied in the civil construction for preparing tile and wall tile, hose and tubes just as domestic gadgets including buckets, bowls, clothes-pin, among others. 


\section{Acknowledgements}

S. L. Favaro is grateful to CNPq (Brazil) for the doctoral fellowship. The authors are thankful to COMCAP-UEM for SEM analysis.

\section{References}

[1] U.S. Census of Bureau (2016) 2013 Annual Survey of Manufactures.

[2] Wagner Jr., J.R. (2009) Multilayer Flexible Packaging: Technology and Applications for the Food, Personal Cares, and Over-the-Counter Pharmaceutical. William Andrew.

[3] Forlin, F.J. and Faria, J.A.F. (2002) Considerações Sobre a Reciclagem de Embalagens Plásticas. Polímeros: Ciência e Tecnologia, 12, 1-10.

[4] Hernandez-Muñoz, P., Catalá, R. and Gavara, R. (1999) Effect of Sorbed Oil on Food Aroma Loss through Packaging Materials. Journal of Agricultural and Food Chemistry, 47, 4370-4374. https://doi.org/10.1021/jf9901791

[5] Marsh, K. and Bugusu, B. (2007) Food Packaging-Roles, Materials, and Environmental Issues. Journal of Food Science, 72, R39-R55.

https://doi.org/10.1111/j.1750-3841.2007.00301.x

[6] Chytiri, S., Goulas, A.E., Riganakos, K.A. and Kontominas, M.G. (2006) Thermal, Mechanical and Permeation Properties of Gamma-Irradiated Multilayer Food Packaging Films Containing a Buried Layer of Recycled Low-Density Polyethylene. Radiation Physics and Chemistry, 75, 416-423. https://doi.org/10.1016/j.radphyschem.2005.07.005

[7] Favaro, S.L., Freitas, A.R., Ganzerli, T.A., Pereira, A.G.B., Cardozo, A.L., Baron, O., Muniz, E.C., Girotto, E.M. and Radovanovic, E. (2013) PET and Aluminum Recycling from Multilayer Food Packaging Using Supercritical Ethanol. The Journal of Supercritical Fluids, 75, 138-143. https://doi.org/10.1016/j.supflu.2012.12.015

[8] Singh, B. and Sharma, N. (2008) Mechanistic Implications of Plastic Degradation. Polymer Degradation and Stability, 93, 561-584. https://doi.org/10.1016/j.polymdegradstab.2007.11.008

[9] Siracusa, V., Rocculi, P., Romani, S. and Rosa, M.D. (2008) Biodegradable Polymers for Food Packaging: A Review. Trends in Food Science \& Technology, 19, 634-643. https://doi.org/10.1016/j.tifs.2008.07.003

[10] Arbelaiz, A., Fernández, B., Ramos, J.A., Retegi, A., Llano-Ponte, R. and Mondragon, I. (2005) Mechanical Properties of Short Flax Fibre Bundle/Polypropylene Composites: Influence of Matrix/Fibre Modification, Fibre Content, Water Uptake and Recycling. Composites Science and Technology, 65, 1582-1592.

https://doi.org/10.1016/j.compscitech.2005.01.008

[11] Duigou, A.L., Pillin, I., Bourmaud, A., Davies, P. and Baley, C. (2008) Effect of Recycling on Mechanical Behaviour of Biocompostable Flax/Poly(L-Lactide) Composites. Composites Part A: Applied Science and Manufacturing, 39, 1471-1478. https://doi.org/10.1016/j.compositesa.2008.05.008

[12] Arao, Y., Yumitori, S., Suzuki, H., Tanaka, T., Tanaka, K. and Katayama, T. (2013) Mechanical Properties of Injection-Molded Carbon Fiber/Polypropylene Composites Hybridized with Nanofillers. Composites Part A: Applied Science and Manufacturing, 55, 19-26. https://doi.org/10.1016/j.compositesa.2013.08.002

[13] Berlin, A.A., Volfson, S.A., Enikolopian, N.S. and Negmatov, S.S. (1986) Principles of Polymer Reinforcement with Fillers. In: Berlin, A.A., Volfson, S.A., Enikolopian, N.S. and Negmatov, S.S., Eds., Principles of Polymer Composites, Springer-Verlag, Berlin, 5-36. 
[14] Favaro, S.L., Ganzerli, T.A., de Carvalho Neto, A.G.V., da Silva, O.R.R.F. and Radovanovic, E. (2010) Chemical, Morphological and Mechanical Analysis of Sisal Fiber-Reinforced Recycled High-Density Polyethylene Composites. Express Polymer Letters, 4, 465-473. https://doi.org/10.3144/expresspolymlett.2010.59

[15] Favaro, S.L., Lopes, M.S., de Carvalho Neto, A.G.V., de Santana, R.R. and Radovanovic, E. (2010) Chemical, Morphological, and Mechanical Analysis of Rice Husk/Post-Consumer Polyethylene Composites. Composites Part A: Applied Science and Manufacturing, 41, 154-160.

https://doi.org/10.1016/j.compositesa.2009.09.021

[16] Najafi, S.K. (2013) Use of Recycled Plastics in Wood Plastic Composites-A Review. Waste Management, 33, 1898-1905. https://doi.org/10.1016/j.wasman.2013.05.017

[17] Feldman, D. and Barbalata, A. (1996) Synthetic Polymers Technology Properties Applications. Chapman \& Hall, London.

[18] Coutinho, F.M.B., Mello, I.L. and Santa-Maria, L.C. (2003) Polietileno: Principais tipos, propriedades e aplicações. Polímeros. Ciência e Tecnologia, 13, 1-13.

[19] Hassan, A., Wahit, M.U. and Chee C.Y. (2003) Mechanical and Morphological Properties of PP/NR/LLDPE Ternary Blend-Effect of HVA-2. Polymer Testing, 22, 281-290. https://doi.org/10.1016/S0142-9418(02)00100-9

[20] De Carvalho Neto, A.G.V., Ganzerli, T.A., Cardozo, A.L., Favaro, S.L., Pereira, A.G.B., Girotto, E.M. and Radovanovic, E. (2014) Development of Composites Based on Recycled Polyethylene/Sugarcane Bagasse Fibers. Polymer Composites, 35, 768-774. https://doi.org/10.1002/pc.22720

\section{Submit or recommend next manuscript to SCIRP and we will provide best service for you:}

Accepting pre-submission inquiries through Email, Facebook, LinkedIn, Twitter, etc. A wide selection of journals (inclusive of 9 subjects, more than 200 journals) Providing 24-hour high-quality service User-friendly online submission system Fair and swift peer-review system Efficient typesetting and proofreading procedure Display of the result of downloads and visits, as well as the number of cited articles Maximum dissemination of your research work

Submit your manuscript at: http://papersubmission.scirp.org/

Or contact msa@scirp.org 